\title{
Karlheinz Rossbacher, Lesen, Schauen, Staunen. Essays über Literatur und Malerei
}

\section{Marc Lacheny}

\section{(2) OpenEdition}

1 Journals

Édition électronique

URL : http://journals.openedition.org/austriaca/663

DOI : 10.4000/austriaca.663

ISSN : 2729-0603

Éditeur

Presses universitaires de Rouen et du Havre

\section{Édition imprimée}

Date de publication : 1 juin 2018

Pagination : 255-256

ISBN : 979-10-240-1233-9

ISSN : 0396-4590

\section{Référence électronique}

Marc Lacheny, "Karlheinz Rossbacher, Lesen, Schauen, Staunen. Essays über Literatur und Malerei », Austriaca [En ligne], 86 | 2018, mis en ligne le 01 juillet 2020, consulté le 29 janvier 2021. URL : http:// journals.openedition.org/austriaca/663; DOI : https://doi.org/10.4000/austriaca.663

Ce document a été généré automatiquement le 29 janvier 2021.

Austriaca. Cahiers universitaires d'information sur l'Autriche 


\title{
Karlheinz Rossbacher, Lesen, Schauen, Staunen. Essays über Literatur und Malerei
}

\author{
Marc Lacheny
}

\section{RÉFÉRENCE}

Karlheinz Rossbacher, Lesen, Schauen, Staunen. Essays über Literatur und Malerei, Vienne, Lehner, 2017, 155 p., ISBN : 978-3-902850-11-9.

1 Professeur émérite en études germaniques à l'université de Salzbourg où il enseigna de 1966 à 2008, Karlheinz Rossbacher est connu pour sa thèse sur Adalbert Stifter, mais aussi pour ses travaux pionniers, largement inspirés de la sociologie de la littérature, sur Heimatkunst et Heimatliteratur, sur les liens entre littérature et libéralisme à Vienne, ainsi que sur les relations entre littérature et bourgeoisie. S'ajoutent à cela ses (ré)éditions d'œuvres de Ludwig Anzengruber, Ferdinand von Saar et Marie von EbnerEschenbach, et sa publication (avec son épouse Constanze) des lettres d'Alexander von Villers, déjà chez Lehner, en 2010.

2 Avec Lesen, Schauen, Staunen, un petit ouvrage très personnel, Karlheinz Rossbacher s'aventure sur un tout autre terrain, celui des interactions entre littérature et peinture, dont la sémiotique (Umberto Eco) a depuis longtemps souligné la convergence, voire la fusion (au moins partielle): la contemplation d'un tableau a inspiré de nombreux écrivains (Bildgedichte) ; à l'inverse, mais plus rarement, des œuvres littéraires ont pu inciter des peintres à mettre ces œuvres en images (Gedichtbilder). Il s'agit donc ici pour l'auteur d'examiner la manière dont les images sont traduites en mots et inversement, donnant naissance à un langage par lequel nous cherchons à saisir notre existence et à comprendre le monde.

Pour donner ne serait-ce qu'une idée de la richesse des perspectives ouvertes par cet ouvrage, nous concentrerons notre propos sur les deux chapitres en lien direct avec 
l'Autriche : l'un est consacré à une mise en regard entre Hofmannsthal et Klimt, l'autre au passage progressif de motifs révolutionnaires à l'opérette viennoise.

Dans le premier chapitre (p. 84-102), Karlheinz Rossbacher, sans parvenir à prouver une relation directe entre Gustav Klimt et Hugo von Hofmannsthal ( Ob Gustav Klimt Hofmannsthals Idylle kannte, ist nicht sicher. Andererseits scheint sich Hofmannsthal, dem so viel an der bildenden Kunst lag, mit Klimt kaum befasst zu haben », p. 95), montre toutefois que l'on peut établir un lien thématique et symbolique entre une esquisse de Klimt, Jurisprudenz, et le petit drame lyrique de Hofmannsthal intitulé Idylle. Rappelant qu'aucune forme d'art - en dehors de la littérature - n'est aussi souvent mentionnée par Hofmannsthal que les arts plastiques («Ich bin ein Dichter, weil ich bildlich erlebe », écrivait-il à l'âge de 20 ans), Rossbacher met ainsi en évidence le fait que Hofmannsthal a inscrit au cœur de sa pièce l'idée fondamentale de la vengeance : le mari trompé se fait justice lui-même. Semblablement, la figure de la Jurisprudenz ébauchée par Klimt s'apparente à une déesse de la vengeance : les furies entourent le condamné, alors que les incarnations de la vérité, de la justice et de la loi, affaiblies, se voient reléguées à l'arrière-plan. Hofmannsthal et Klimt s'éloignent des représentations traditionnelles, équilibrées, de la déesse Justitia pour privilégier la dimension vengeresse, remplaçant ainsi le gerecht par le gerächt.

5 L'autre chapitre (p. 112-138) couvre un vaste spectre allant du satiriste français HenriAuguste Barbier (1805-1882) - connu surtout pour ses Iambes, poèmes satiriques inspirés par les "Trois Glorieuses » - à la célébrissime opérette Die Fledermaus de Johann Strauß, en passant par La Liberté guidant le peuple d'Eugène Delacroix, la pièce Freiheit in Krähwinkel de Johann Nestroy et le tableau monumental Der Triumph der Ariadne de Hans Makart, mis en résonance avec le tableau de Delacroix: "So wie Delacroix' Figur konkretisierte Allegorie ist, Göttin der Freiheit und zugleich Pariser Straßenfrau, so ist Ariadne mythische Figur und zugleich Wienerin» (p. 128). L'auteur montre ainsi le recul progressif, au fil du XIX siècle, de l'élan révolutionnaire en faveur d'un hédonisme débridé et d'une soif d'harmonie (incarnés par Die Fledermaus) visant à détourner les spectateurs des crises politiques et sociales : « Glücklich ist, wer vergißt, was doch nicht zu ändern ist! »

6 En résumé, ce petit ouvrage soigneusement édité constitue une belle invite à lire ou à relire, à voir ou à revoir par soi-même les œuvres et tableaux évoqués, et à s'interroger de manière critique sur leurs interactions, réelles ou supposées. 